\title{
Comparative study of the optical behavior of a porphyrin encapsulated in sol-gel silica coatings and in solution as a function of $\mathrm{pH}$
}

\author{
N. Carmona ${ }^{\text {a, }{ }^{*}, \text { M.A. Villegas }}{ }^{\text {b }}$, E.F. Montero ${ }^{\text {c }}$, M.A. García ${ }^{\text {d }}$, J. Llopis ${ }^{a}$ \\ ${ }^{a}$ Facultad de Ciencias Físicas, Universidad Complutense de Madrid, Spain \\ ${ }^{\mathrm{b}}$ IH-CCHS, Consejo Superior de Investigaciones Científicas, Madrid, Spain

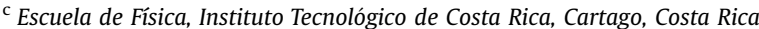 \\ d Instituto de Cerámica y Vidrio, CSIC and Instituto de Magnetismo Aplicado UCM, Madrid, Spain
}

\section{H I G H L I G H T S}

- Porphyrin-doped silica coatings were prepared by sol-gel.

- Films optical properties were studied and compared to the behavior of the molecule in solution.

- A quasi-linear behavior throughout the $\mathrm{pH}$ range studied was found.

- Luminescent emission peak and molar absorptivity were maximum at slightly lower wavelength than molecule in solution.

\section{A R T I C L E I N F O}

\section{Article history:}

Received 5 April 2016

Received in revised form

8 July 2016

Accepted 16 July 2016

Available online 29 July 2016

\section{Keywords:}

Sol-gel

Thin coatings

Porphyrin

Optical properties

Absorbance

Luminescence
G R A P H I C A L A B S T R A C T

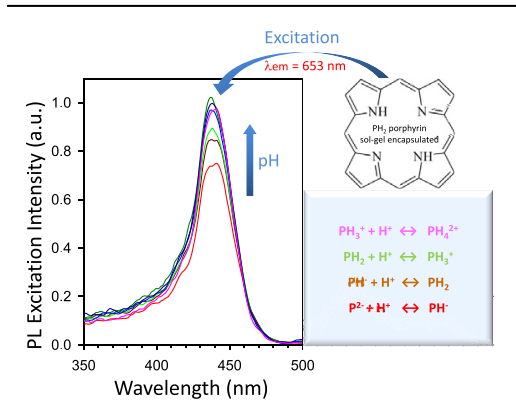

\begin{abstract}
A B S T R A C T
We report a comparative optical spectral study as a function of $\mathrm{pH}$ on a porphyrin encapsulated in a solgel matrix and in methanol solution. Its response has been discussed in terms of pH-sensitivity as a function of the coatings thickness. Comparison with the behavior of such porphyrin in methanol solution is also included.

Optical properties of the porphyrin doped coatings show a quasi linear behavior throughout the $\mathrm{pH}$ range studied. Luminescent emission of doped coatings has its maximum peak at a slightly lower wavelength compared with the response in liquid medium (methanol solution), while in the excitation spectra no clear tendency was observed for different $\mathrm{pH}$. Coatings doped with $1 \mathrm{wt} \%$ porphyrin fulfill Lambert-Beer law, although the molar absorptivity of the encapsulated porphyrin in the coatings is slightly lower than in methanol solution.
\end{abstract}

() 2016 Elsevier B.V. All rights reserved.

\section{Introduction}

The sol-gel method is a low-cost chemical route which enables the encapsulation of organic molecules [1,2]. In many cases, such molecules preserve their properties once immobilized inside the

\footnotetext{
* Corresponding author.

E-mail address: n.carmona@fis.ucm.es (N. Carmona).
}

sol-gel material [3]. Cationic porphyrins and their metal complexes [4] attract significant attention because their structure makes them suitable candidates for optical and catalytic applications. For instance, due to their unusual luminescence, they have been applied for photosensitizers [5] and sensors [6-8], among others. In this respect, the molecules are preferably immobilized inside a porous network to obtain easy to use materials provided with a better applicability, photostability or chemical durability [9]. 
However, the luminescence properties of many porphyrins are strongly affected by the particular structure of the porous matrix [10]. Therefore, a comparison study of the porphyrin molecules behavior in their free form and once encapsulated is necessary $[8,11]$. Other applications of the porphyrin selected in the present work can be found in: quantitative determination of cadmium [12], ascorbic acid determination [13], electrocatalysis [14], biomedical and biochemical applications [15-17], cationic clays [18] and new sol-gel materials for electrodes and optical sensors [19,20].

Among the different materials suitable for porphyrin immobilization, thin sol-gel coatings have proven to be optimum [21]. Solgel coatings advantages are well known: easy preparation at room temperature, low cost processing equipments, good mechanical adherence to the substrate (usually common glass slides), and aptitude of the sols to coat surfaces of different size, shape and geometry. The use of very pure chemical reagents such as alkoxides and/or alkylalkoxides of silicon, zirconium, aluminum, boron, etc., which constitute the coating matrix, ensures the purity and stability of the doped coating. Therefore, these sol-gel coatings are materials with good mechanical, thermal and optical properties, in addition to a chemical stability and adequate porosity [22]. This latter property is very interesting since the encapsulation of the dopant, in this case a porphyrin, depends on such porosity, which ensures the physical contact of the encapsulated dopant with other chemical species coming from the exterior.

The objective of this work is, on the one hand, the preparation of a porphyrin doped sol-gel silica coating and, on the other hand, the study of its optical behavior, both in an alcoholic solution and once encapsulated in the sol-gel coating. The porphyrin selected was 5,10,15,20-tetrakis (1-methyl-4-pyridil)-21H, 23H-porphyrin. The main aim of this comparison study is to clarify the porphyrin optical behavior under different environments, liquid and solid, and to point out similarities or differences related to other organic dopants also encapsulated in sol-gel thin coatings [23] to check their ability as potential optical material.

\section{Experimental methods}

Silica matrices of the thin coatings were prepared from a sol whose components were: silicon tetraethoxide (TEOS, $\left.\mathrm{Si}\left(\mathrm{OC}_{2} \mathrm{H}_{5}\right)_{4}\right)$, hydrochloric acid $\mathrm{HCl} 3 \mathrm{M}$ and methanol (MeOH) in molar ratio $1: 4: 8$, and deionized water to accomplish stoichiometric TEOS hydrolysis. The first step consists on a pre-hydrolysis of the silicon alkoxide diluted with methanol and $\mathrm{HCl} 3 \mathrm{M}$, which catalyzes the reaction, at room temperature under constant stirring to warrant the sol homogenization. A methanol solution (1 wt \% respect the final silica content of the sol) of the p-tosilate salt of the $5,10,15,20$ tetrakis (1-methyl-4-pyridil)-21H, 23H-porphyrin (herein after the porphyrin, Fig. 1) was prepared and added to the pre-hydrolyzed TEOS solution, i.e. when the solution temperature increased spontaneously at about $5{ }^{\circ} \mathrm{C}$ from room temperature, as a consequence of the hydrolysis reaction heat release.

After 30 min of continuous stirring, the homogeneous sol was ready to be used for depositing thin coatings upon common soda lime silicate glass slides. Chemically cleaned glass slides were coated at room temperature by dip-coating into the sol at different constant rates in the $5-30 \mathrm{~cm} \mathrm{~min}^{-1}$ range. After drying $10 \mathrm{~min}$ at room temperature, the coated slides were heat-treated for 3 days at $60{ }^{\circ} \mathrm{C}$ in a forced air stove. Thicknesses of the doped coatings were estimated by means of the corresponding reflectance spectra (fringe method) and they vary in the 100-550 $\mathrm{nm}$ range.

Additionally, another porphyrin solution in a mixture of methanol and deionized water (volume ratio 1:4) was prepared. Aqueous phase was a pH buffered solution (pHydrion Buffers ${ }^{\circledR}$, Micro Essential Laboratory Inc. USA), also used to analyze the

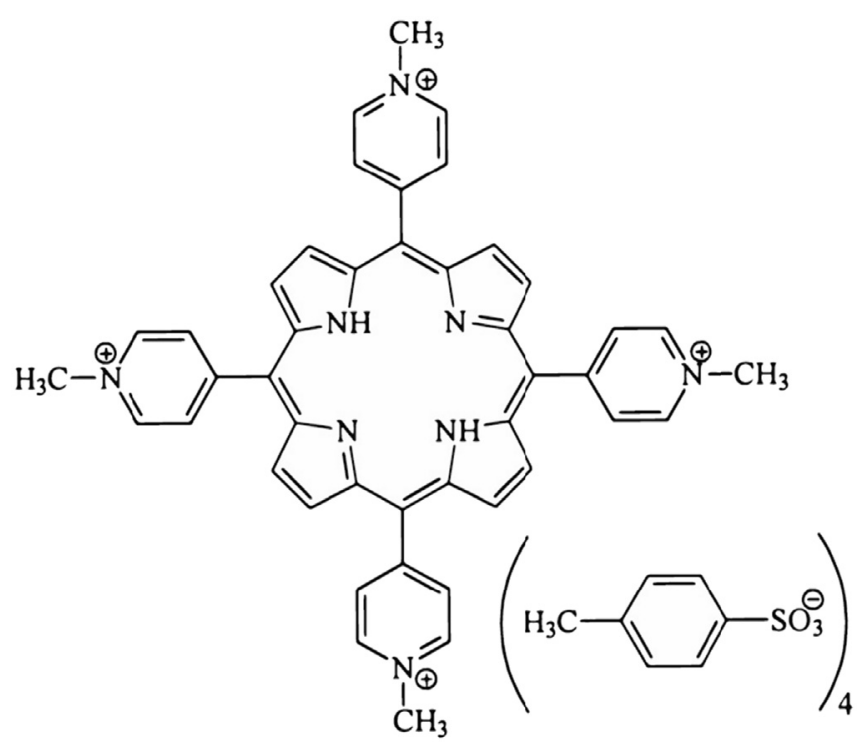

Fig. 1. Molecular structure of the porphyrin used as a dopant of the sol-gel thin coatings.

coatings behavior. The concentration of other porphyrin solutions ranged between $5.0 \times 10^{-4} \mathrm{M}$ and $3.0 \times 10^{-5} \mathrm{M}$.

Optical absorption spectra of both solutions and coatings were recorded with a Shimazu UV 3100 spectrophotometer provided with an integrating sphere. Solutions spectra were recorded in the wavelength range of $200-750 \mathrm{~nm}$, while coatings spectra were recorded in the $280-750 \mathrm{~nm}$ range. Luminescence spectra (excitation and emission) were recorded with a Perkin-Elmer LS-5B fluorescence spectrometer. Excitation spectra of both solutions and coatings were recorded in the wavelength range of $230 \mathrm{~nm}$ to $\sim 15 \mathrm{~nm}$ below the emission wavelength selected. Emission spectra were recorded from $\sim 15 \mathrm{~nm}$ above the excitation wavelength selected up to $720 \mathrm{~nm}$.

\section{Results}

Optical behavior of the porphyrin mentioned above has been studied in the $0-13.4 \mathrm{pH}$ range in solution and encapsulated in the thin sol-gel coating, since both show sensitivity against $\mathrm{pH}$ changes. Solubility and chemical structure of the porphyrin molecule depend on the $\mathrm{pH}$. The porphyrin macromolecule can be considered as an ampholyte with two pyrrolic nitrogen atoms able to accept protons, and two NH groups able to lose them (Fig. 2).

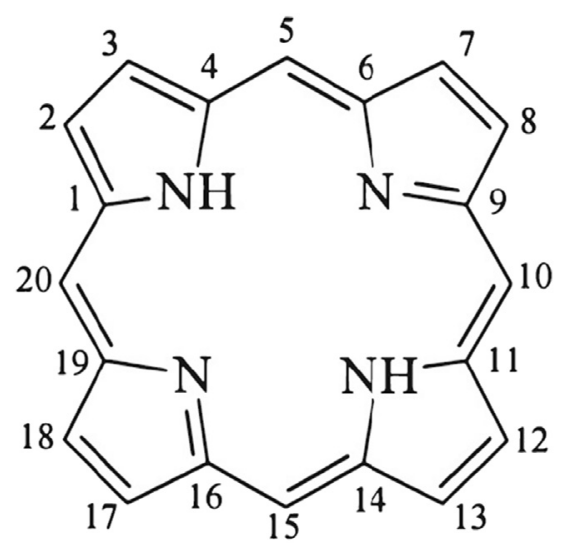

Fig. 2. Free base molecular structure of the porphyrin $\left(\mathrm{PH}_{2}\right)$. 
The protonation/deprotonation reactions of the porphyrin can be resumed as follows:

$\mathrm{P}^{2-}+\mathrm{H}^{+} \leftrightarrow \mathrm{PH}^{-} \mathrm{K}_{1}$

$\mathrm{PH}^{-}+\mathrm{H}^{+} \leftrightarrow \mathrm{PH}_{2} \mathrm{~K}_{2}$

$\mathrm{PH}_{2}+\mathrm{H}^{+} \leftrightarrow \mathrm{PH}_{3}^{+} \mathrm{K}_{3}$

$\mathrm{PH}_{3}^{+}+\mathrm{H}^{+} \leftrightarrow \mathrm{PH}_{4}^{2+} \mathrm{K}_{4}$

Theoretically the porphyrin can undergo four transformations among its five polyprotic forms. Some equilibrium constants in solution have been found in the literature [24,25]: $\mathrm{pK}_{1}=0.7$ and $\mathrm{pK}_{2}=1.8$. These values indicate that this porphyrin possesses an acid character more intense than other porphyrins with anionic groups [26]. This is due to the electrostatic repulsion that cationic groups (such as $\equiv \mathrm{N}\left(\mathrm{CH}_{3}\right)^{+}$) perform on the $\mathrm{H}_{3} \mathrm{O}^{+}$ions that would protonate the porphyrin molecule. The repulsion force also avoids the formation of porphyrin dimmers in acid media [24]. The cationic groups attract $\mathrm{OH}^{-}$groups in neutral and basic media, which favors the porphyrin ring deprotonation and consequently, lower values of $\mathrm{pK}_{3}$ and $\mathrm{pK}_{4}$. On the contrary, other porphyrins react in the opposite way and their $\mathrm{pK}_{3}$ and $\mathrm{pK}_{4}$ are larger [27]. The formation of dimmers of the porphyrin of the present work could be favored by a partial electrostatic stabilization when the negative charge of the porphyrin ring is coupled with the positive charged groups from the external part of the molecule.

\subsection{Optical behavior of porphyrin solutions}

\subsubsection{Optical absorption}

The porphyrin used in the present work is a water soluble mesosubstituted porphyrin. Likewise, it is also soluble in polar organic solvents, e.g. methanol [28]. The optical absorption spectrum of the porphyrin in methanol solution shows a Soret band $(\sim 390-440 \mathrm{~nm})$ and low intensity $Q$ bands $(500-660 \mathrm{~nm})$. The evaluation of the optical absorption of the porphyrin in methanol as a function of concentration (Lambert-Beer law) established that the Soret band does not follow the law for concentration above $5.0 \times 10^{-5} \mathrm{M}$. This result is coherent with the work of Pasternak et al. [29] carried out in aqueous solution. Therefore, such limit in the concentration was used for recording the spectrum showed in Fig. 3 in which the resolution of the low intense $Q$ bands has been improved (Table 1).

The maximum of the Soret band appears at $424 \mathrm{~nm}$, the shoulder at about $360 \mathrm{~nm}$ corresponds to the $\mathrm{N}$ band and the bands

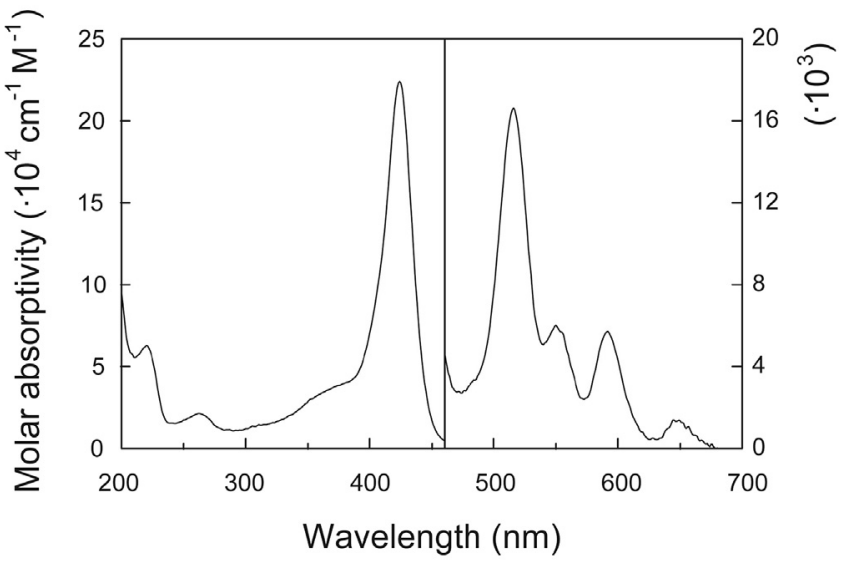

Fig. 3. Molar absorptivity of the porphyrin in methanol solution.
Table 1

Features of the porphyrin absorption bands in methanol solution.

\begin{tabular}{lllll}
\hline Band & $\lambda_{\max }(\mathrm{nm})$ & $\mathrm{E}_{\max }(\mathrm{eV})$ & $\varepsilon\left(\mathrm{cm}^{-1} \mathrm{M}^{-1}\right)$ & Rel. Int. \\
\hline Q I & 645 & 1.92 & 1380 & 0.6 \\
Q II & 592 & 2.09 & 5700 & 2.5 \\
Q III & 550 & 2.25 & 6020 & 2.7 \\
Q IV & 516 & 2.40 & 16620 & 7.4 \\
Soret & 424 & 2.90 & 224000 & 100 \\
L & 263 & 4.71 & 21220 & 9.5 \\
M & 220 & 5.64 & 62660 & 28.0 \\
\hline
\end{tabular}

at 263 and $220 \mathrm{~nm}$ are assigned to the L and $\mathrm{M}$ bands, respectively. Regarding the Q bands, their wavelengths are in the $645-516 \mathrm{~nm}$ range with relative intensities IV $>$ III $>$ II $>$ I following the pattern of references $[27,30]$. Both wavelengths and intensities are consistent with those reported by Makarska et al. for phorphyrins in methanol solution [28].

\subsubsection{Luminescence (excitation and emission)}

Concerning the luminescence excitation spectrum in $5.0 \times 10^{-5} \mathrm{M}$ methanol solution, Fig. 4 shows bands L, M, Soret and Q (IV, III, II). Q I band cannot be observed since the emission wavelength taken $(653 \mathrm{~nm})$ is too near to the Q I absorption band $(\sim 650 \mathrm{~nm})$. The corresponding emission spectrum (Fig. 4) is dominated by an intense band peaked at $653 \mathrm{~nm}$ and another weaker at about $713 \mathrm{~nm}$ (Table 2). The decreasing of the Soret excitation band with respect to the same absorption band, indicates that part of the energy absorbed by this band is released by means of non-radiative processes. Moreover, this mechanism is more effective in the Soret band than in the Q bands, in which a smaller decrease was found. For more concentrated methanol solutions $\left(2.0 \times 10^{-4} \mathrm{M}\right)$, the relative decreasing is more accused, and the Soret band widens, probably due to the formation of dimmers or trimmers [31], even though the Lambert-Beer law is fulfilled.

\subsubsection{Absorption-pH behavior}

A $4.0 \times 10^{-5} \mathrm{M}$ solution was prepared to study the absorption spectra of the porphyrin in methanol solution as a function of $\mathrm{pH}$. The maximum and intensity of the Soret band varies with $\mathrm{pH}$. Among the Q bands, Q IV and Q I change their intensity strongly. Fig. 5 shows the evolution of the Soret band with the pH. The molar absorptivity of the Soret band presents an important change in the $0-2 \mathrm{pH}$ range, while the changes in wavelength indicate two main

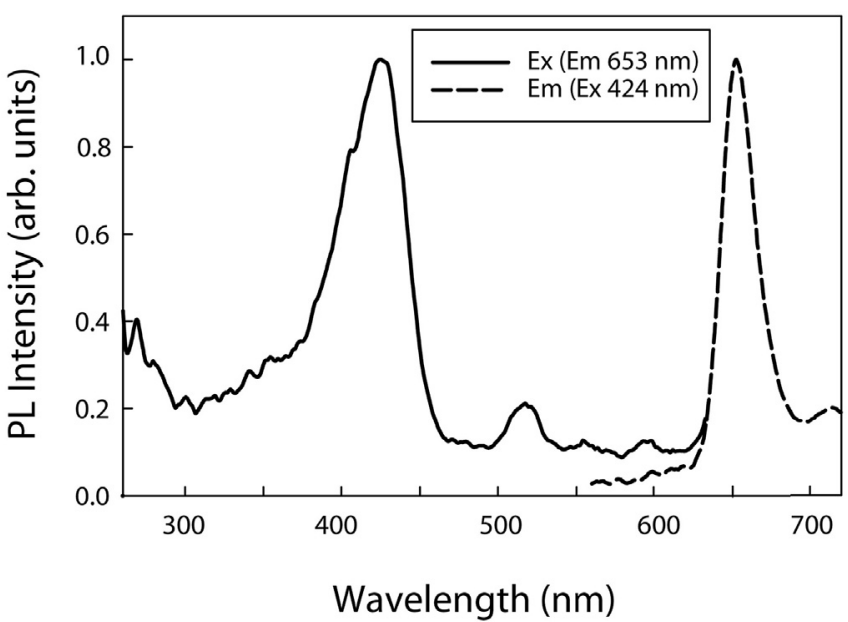

Fig. 4. Normalized excitation and emission spectra of the porphyrin in methanol solution. 
Table 2

Features of the excitation bands of the porphyrin in methanol solution.

\begin{tabular}{llllll}
$\lambda_{\max }(\mathrm{nm})$ & 269 & 425 & 517 & 555 & 596 \\
$\mathrm{E}_{\max }(\mathrm{eV})$ & 4.61 & 2.92 & 2.40 & 2.23 & 2.08 \\
Rel. Int. & 40 & 100 & 19 & 10.6 & 10.6 \\
\hline
\end{tabular}

regimes: firstly, between $\mathrm{pH} 0.5-1.4$ (the wavelength changes from 446 to $423 \mathrm{~nm}$ ), and secondly, between $\mathrm{pH}$ 1.5-3.0 (the wavelength changes from 423 to $435 \mathrm{~nm}$ ).

These two regimes are connected with the two polyprotic transformations ( $\mathrm{pK}_{1}$ and $\mathrm{pK}_{2}$ ) mentioned above. Moreover, other changes occur at $\mathrm{pH}=4-6$ and at $\mathrm{pH}>12$, related to the other two polyprotic transformations from the free base form to monoanionic form $\left(\mathrm{pK}_{3}\right)$, and from monoanionic form to dianionic form $\left(\mathrm{pK}_{4}\right)$. Therefore, the estimated $\mathrm{pK}$ values are:

$\mathrm{pK}_{1}=0.8 ; \mathrm{pK}_{2}=2.0 ; \mathrm{pK}_{3}=5.5 ; \mathrm{pK}_{4} \sim 13$

The estimation was made taking into account the evolution of both the Soret and Q bands, although the changes of the Soret one were considered priority. In general, the estimated error is about $0.4 \mathrm{pH}$ units, and $1 \mathrm{pH}$ unit for the $\mathrm{pK}_{4}$ value.

As for the wavelength of the $\mathrm{Q}$ bands concern, they can be split into two groups: bands IV and I, and bands II and III, whose behavior is the opposite one each other throughout the $\mathrm{pH}$ range. However, the pair of bands IV and III and the pair II and I, show the maximum and minimum intensity for the same $\mathrm{pH}$ values. Considering the molar absorptivity, Q I and IV bands exhibit the most significant variations in the $\mathrm{pH}$ range $0-1.5$ and for $\mathrm{pH}>12$, while Q II and III bands vary mainly in the $\mathrm{pH}$ range $0-2$; Q II band changes in the $\mathrm{pH}$ range $5-6$ and for $\mathrm{pH}>12$; and $\mathrm{Q}$ III band increases in the $\mathrm{pH}$ range $7-10$. Taking into account the transformations that include simultaneous changes of wavelength and molar absorptivity of $\mathrm{Q}$ bands, they are consistent with the $\mathrm{pH}$ ranges in which the Soret band changes. This fact agrees the relation between the Soret band changes and the polyprotic transformations of the porphyrin molecule.

In the $\mathrm{pH}$ range $6-11$, the molar absorptivity of the Soret band changes, even though the wavelength remains constant. This fact suggests some non-polyprotic transformation, which is supported by the $\mathrm{Q}$ bands molar absorptivity variations in the $\mathrm{pH}$ range $7-11$.

\subsubsection{Luminescence-pH behavior}

Both intensity and position of emission and excitation maxima change with the $\mathrm{pH}$. The most important variation occurs in the $\mathrm{pH}$

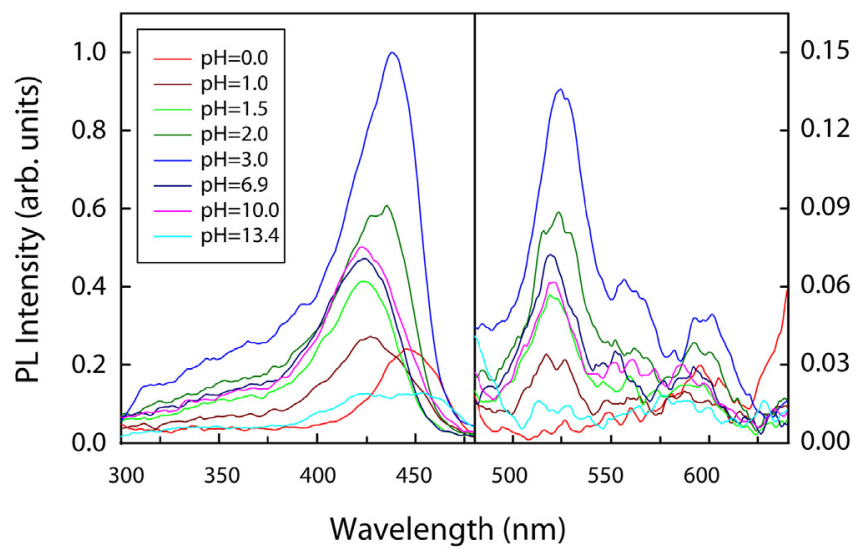

Fig. 6. Excitation spectra of the porphyrin in methanol solution for different $\mathrm{pH}$ values.

range $1-4$ followed by minor changes in the $\mathrm{pH}$ range $5-6$ and for $\mathrm{pH}>11$. Obviously, major part of these changes are associated with the polyprotic transformations of the porphyrin. It is noticeable that, in general, the excitation spectra show the same bands as the corresponding absorption spectra, but the relative intensity of the Soret band respect to that of $\mathrm{Q}$ bands decreases quite in the excitation spectra.

Soret and $\mathrm{Q}$ bands of the porphyrin excitation spectra for different $\mathrm{pH}$ values in methanol solution are shown in Fig. 6. The intensity of the Soret bands is maximum at $\mathrm{pH}=3$, while the intensities of the $\mathrm{Q}$ bands are 7 times lower.

Nevertheless, this difference in relative intensities of the excitation spectra is smaller than in the absorption ones, where the intensity of the $\mathrm{Q}$ bands is 12 times smaller than that of the Soret bands. The variation of the intensity and wavelength of the Soret bands induced by the $\mathrm{pH}$ change are connected with the changes of the electronic levels structure and are very similar to those of the absorption spectra. The first polyprotic transformation takes place at $\mathrm{pH}=0.5-1\left(\mathrm{pK}_{1}\right)$, and the second one at $\mathrm{pH}=1.5-2\left(\mathrm{pK}_{2}\right)$. In the $\mathrm{pH}$ range 5-6 the change associated with $\mathrm{pK}_{3}$ takes place, and then at $\mathrm{pH}=13.4$ the intensity decreases and the wavelength increases $\left(\mathrm{pK}_{4}\right)$. The four $\mathrm{pK}$ values can be deduced in a similar way as mentioned previously, and the results obtained are coherent with the data reported above.

The emission spectra of the porphyrin in methanol solution $\left(\lambda_{\text {exc }}=420 \mathrm{~nm}\right)$ for different $\mathrm{pH}$ are shown in Fig. 7 . This figure indicates that the $\mathrm{pH}$ variation affects the shape, intensity and wavelength of the emission band.
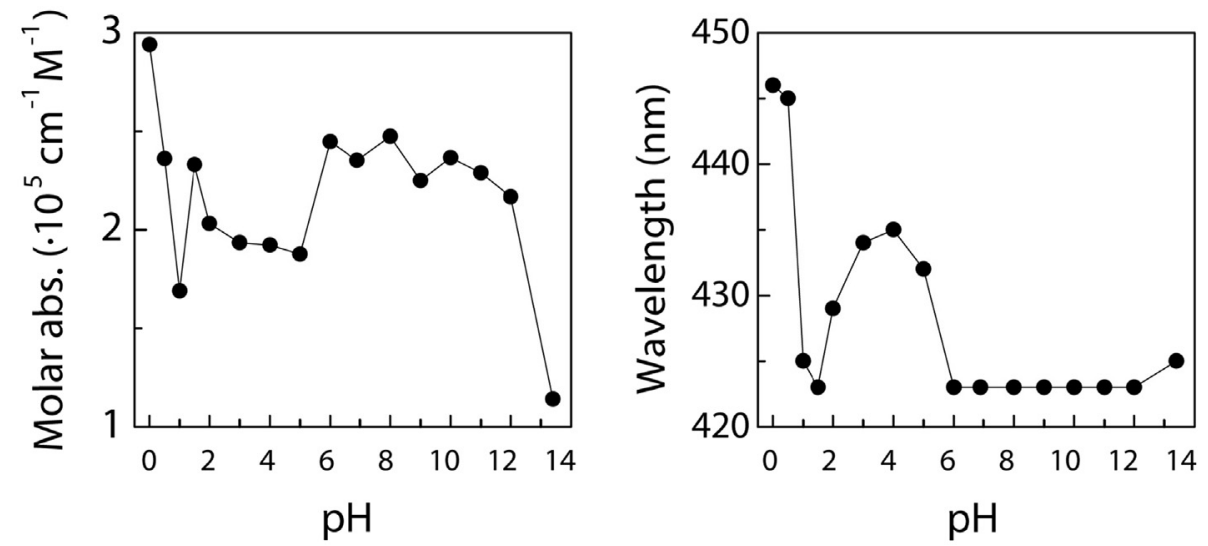

Fig. 5. Molar absorptivity and wavelength of the Soret band maximum of the porphyrin in methanol solution as a function of $\mathrm{pH}$ 


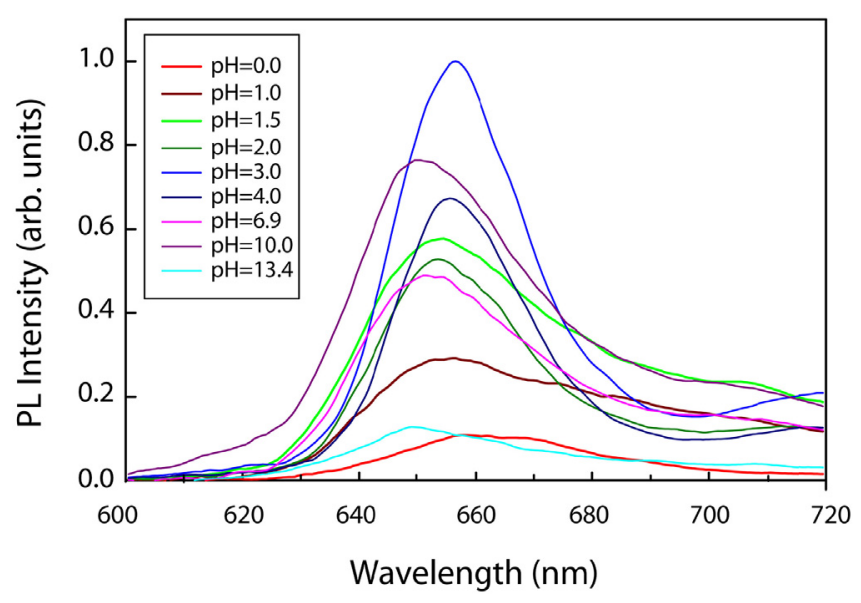

Fig. 7. Emission spectra of the porphyrin in methanol solution for different $\mathrm{pH}$ values.

The maximum emission peak is at about $655 \mathrm{~nm}$ for $\mathrm{pH}=3$. Other minor emission band appears near $620 \mathrm{~nm}$ and 700-720 nm. The variation with the $\mathrm{pH}$ of the main emission band at $655 \mathrm{~nm}$ is similar to those of the excitation bands, i.e., noticeable intensity changes in the $\mathrm{pH}$ ranges $0.5-1.5 ; 2-3 ; 5-6$ and $11-13.4$ associated with the $\mathrm{pK}$ values. Moreover, the wavelength changes with the $\mathrm{pH}$ are clearly connected with the two first polyprotic transformations, while the others are only a hint.

\subsection{Optical behavior of porphyrin doped coatings}

\subsubsection{Absorption-pH behavior}

The absorption spectra of the porphyrin doped coating (1 wt \% porphyrin, $658 \mathrm{~nm}$ thickness) for different pH are shown in Fig. 8. The maximum of the Soret band is about constant at $433 \mathrm{~nm}$, even though the intensity increases. This behavior is different from that in methanol solution, in which also the maximum position changes with $\mathrm{pH}$.

According to the former interpretation, the free base form in solution shows the Soret band maximum near the Soret band maximum of the porphyrin encapsulated in the coating. Therefore, most of the porphyrin molecules in the coating are in their free base form. Nevertheless, the intensity of the band in the coating increases with $\mathrm{pH}$, which can be explained by a partial transformation of the free base forms into monoanionic forms. Thus, when $\mathrm{pH}$ increases, some porphyrin molecules possess a configuration with higher molar absorptivity and the final effect is an

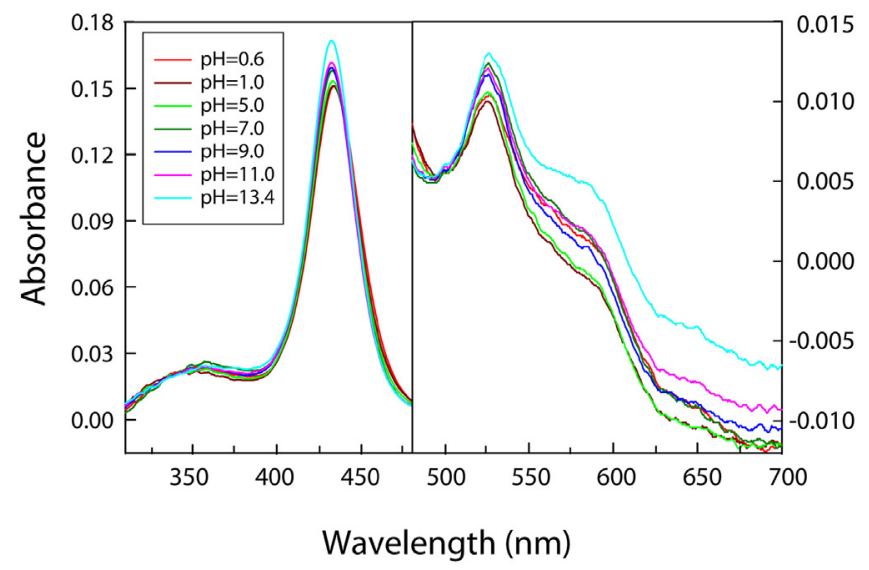

Fig. 8. Absorption spectra of a porphyrin doped coating once dipped into different $\mathrm{pH}$ buffered solutions.
Table 3

Features of Soret and Q absorption bands of porphyrin doped coatings.

\begin{tabular}{lllll}
\hline Band & $\mathrm{pH}$ & $\lambda_{\max }(\mathrm{nm})$ & $\mathrm{E}_{\max }(\mathrm{eV})$ & Rel. Int. \\
\hline Soret & 1.0 & 434 & 2.86 & 88 \\
& 13.4 & 432 & 2.87 & 100 \\
Q IV & 1.0 & 526 & 2.36 & 6.1 \\
& 13.4 & 526 & 2.36 & 6.7 \\
Q II & 13.4 & $\sim 590$ & $\sim 2.10$ & 4.7 \\
\hline
\end{tabular}

absorption intensity increase. In relation with the $\mathrm{Q}$ bands of the doped coatings, their behavior is similar to the Soret bands, and only an intensity increase has been detected with the $\mathrm{pH}$. Relative intensity of the Q bands is IV > II > I at about 526, 590 and $650 \mathrm{~nm}$, respectively. Q III band is probably overlapped with the Q II band.

Negative absorption values in Fig. 8 result from the subtraction of the coatings spectra respect the glass substrate spectrum. For a given coating thickness, the measurement is associated with a maximum deviation of 0.01 absorption units, as a consequence of the different reflectance and interference processes of the monochromatic beam with both systems. The combined effect of this deviation, the low intensity of the $Q$ bands and the porphyrin luminescence can explain the observation of the negative absorption data found.

Table 3 summarizes the most important features of the absorption spectra of doped coatings; $\mathrm{pH}$ at which maximum wavelengths occur and asymmetry factors are also shown.

Comparison of maximum positions of Soret and $\mathrm{Q}$ bands in doped coatings and methanol solution for a given polyprotic specie, indicate some shifts, which do not take place for the same $\mathrm{pH}$ values, and even some of them are missing. Thus, the dominant specie of the porphyrin doped coating is the free base form [32]. The shifts detected are lower than $0.04 \mathrm{eV}$, i.e., the wavelength of the absorption maximum of the porphyrin in solution is slightly affected by the solid thin coating environment.

One aspect of the doped coatings to be clarified is their behavior against dynamic $\mathrm{pH}$ changes. To perform this study, the Soret absorption band was selected to be monitored in doped coatings submitted to different $\mathrm{pH}$ buffered solutions. The experimental pattern followed these steps: 1 ) hydration of the doped coating for $1 \mathrm{~h}$ in distilled water; 2) coating dipping into the buffered solution of lowest pH during $5 \mathrm{~min}$; 3 ) drying and recording of the absorption spectra; 4) repetition of steps 2 and 3 with the immediately-higher-pH-buffered solution and so on up to the buffered solution of $\mathrm{pH}=13.4$. This sequence is named " $\mathrm{pH}$ increasing", while the opposite from high $\mathrm{pH}$ to low $\mathrm{pH}$ is named "pH decreasing". In Fig. 9 the evolution of the doped coatings response is shown. The lowest intensity of the Soret absorption band at $433 \mathrm{~nm}$ takes place for low $\mathrm{pH}$ and increases monotonically with the $\mathrm{pH}$. Throughout the two cycles of " $\mathrm{pH}$ increasing" and " $\mathrm{pH}$ decreasing" the low hysteresis observed in Fig. 9 indicates that the process could be considered almost reversible, even though in the acid $\mathrm{pH}$ range the differences are slightly larger. In relation with the wavelength of the Soret band, it shifts very slightly with the $\mathrm{pH}$, both in the "pH increasing" and "pH decreasing" cycles. This fact supports that the porphyrin molecules are partially transformed from the free base form to the monoanionic form.

To check the weathering of the doped coatings during a reversible process under different $\mathrm{pH}$ media, the coating was dipped for 5 min 20 times into two buffered solutions of extreme $\mathrm{pH}=1$ and $\mathrm{pH}=13.4$. The Soret absorption band showed the highest variations for the two extreme $\mathrm{pH}$ in such a way that the variations increased in the latest cycles, i.e., sensitivity of the doped coatings increases with the number of cycles. The $\mathrm{Q}$ absorption bands (Q IV at $525 \mathrm{~nm}$ and Q II at $590 \mathrm{~nm}$ ) vary in a less extent than 


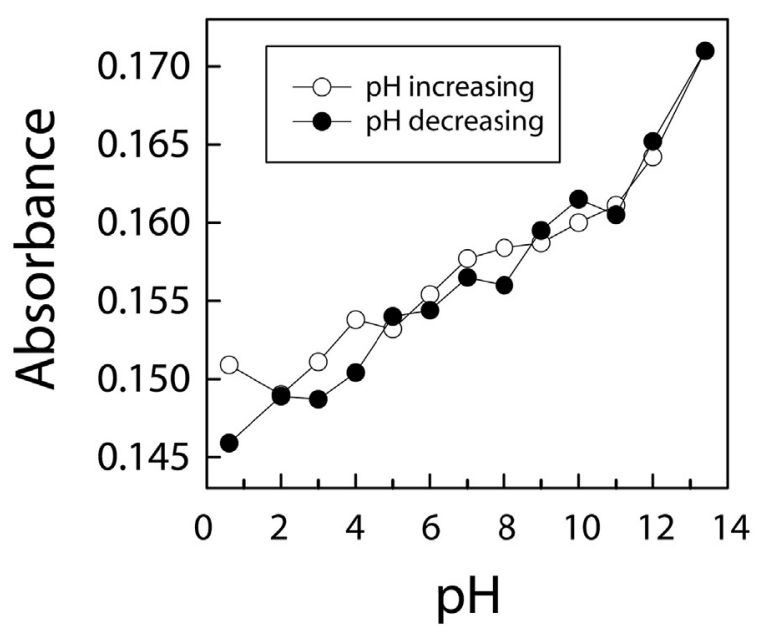

Fig. 9. Evolution of the Soret absorption band of the porphyrin doped coating $(433 \mathrm{~nm})$ against dynamic $\mathrm{pH}$ change.

the Soret band, and a clear tendency was not observed. It should be pointed out that the intensity of the Soret band does not decrease after the dipping cycles, which means that no significant losses by leaching or degradation of the porphyrin molecule took place.

\subsubsection{Luminescence-pH behavior}

Luminescence spectra of doped coatings are sensitive to $\mathrm{pH}$ changes and their behavior is different to that of porphyrin in methanol solution. The excitation spectra were recorded at the emission maximum, and the emission spectra were recorded at the excitation corresponding to the Soret band.

The excitation spectra $\left(\lambda_{\mathrm{em}}=653 \mathrm{~nm}\right)$ of a doped coating $658 \mathrm{~nm}$ thickness is shown in Fig. 10. The Soret band maximum appears at $436 \mathrm{~nm}$, for the Q IV band at $540 \mathrm{~nm}$ and for the Q II band at $590 \mathrm{~nm}$, whatever the $\mathrm{pH}$ of the buffered solution used for dipping the coatings. The intensity of these bands is constant, except the Soret one which increases with the $\mathrm{pH}$, yet without a clear tendency.

The emission spectra of the doped coating $\left(\lambda_{\text {exc }}=433 \mathrm{~nm}\right)$ for different $\mathrm{pH}$ are shown in Fig. 11. The main emission band is centered at about $654 \mathrm{~nm}$, and another very weak band appears near $710 \mathrm{~nm}$. The shape of the emission bands is practically constant, while the intensity slightly changes in the $\mathrm{pH}$ range $7-8$.

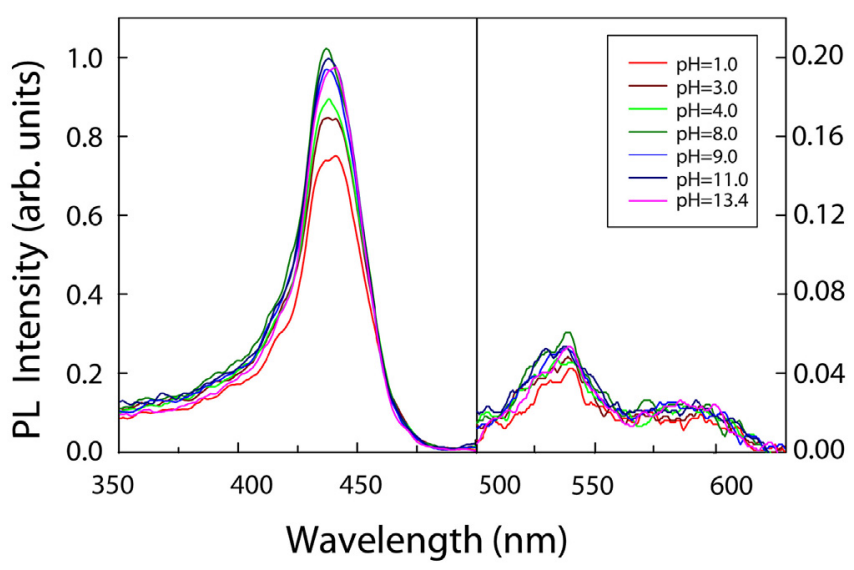

Fig. 10. Excitation spectra of the porphyrin doped coating for different $\mathrm{pH}$ values for $\left(\lambda_{\mathrm{em}}=653 \mathrm{~nm}\right)$.

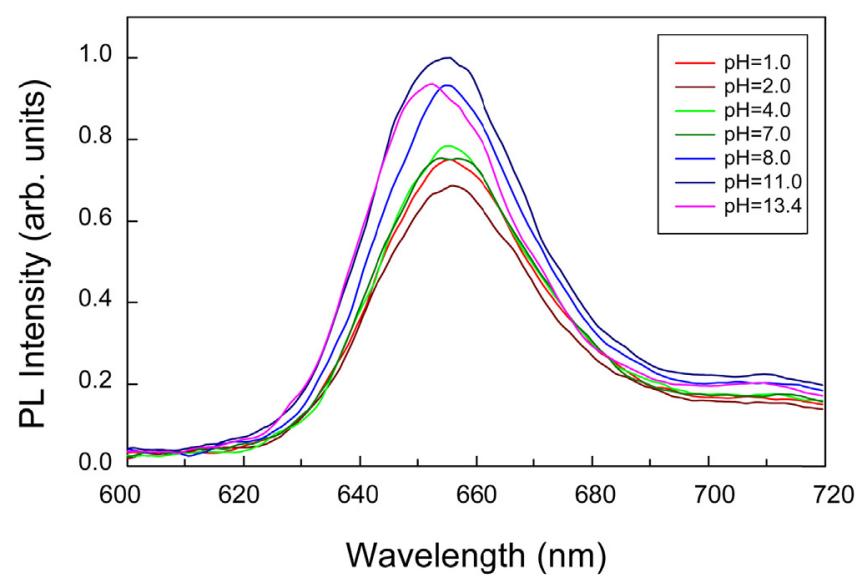

Fig. 11. Emission spectra of the porphyrin doped coating for different $\mathrm{pH}$ values $\left(\lambda_{\mathrm{ex}}=433 \mathrm{~nm}\right)$

\subsubsection{Absorption-thickness behavior}

The breach of the Lambert-Beer law can be due to several causes: low signal/noise ratio, molecular aggregates formation (dimmers, trimmers), inappropriate $\mathrm{pH}$ control, and strong interaction molecule/sol-gel matrix. In fact, previous works pointed out the formation of aggregates in porphyrin doped sol-gel materials [33]. The study of the relationship between absorption of doped coatings and their thickness was undertaken with coatings of 8 different thicknesses ranging from 254 to $858 \mathrm{~nm}$. Prior to the spectra recording, the coatings were dipped into a $\mathrm{pH} 7$ buffered solution for $5 \mathrm{~min}$. The corresponding absorption spectra showed a maximum at $433 \mathrm{~nm}$ (Soret band), whose intensity increases constantly with the coatings thickness. Q bands are strongly modified by the different thicknesses and no clear tendency was observed. The absorption of the Soret band maxima of doped coatings at $433 \mathrm{~nm}$ are shown in Fig. 12.

This linear relationship indicates the Lambert-Beer law accordance for the porphyrin concentration used and the thickness range studied. The molar absorptivity of the porphyrin, once encapsulated in the solid thin coating, can be estimated taking $1.9 \mathrm{~g} \mathrm{~cm}^{-3}$ as the average density of the coatings. Thus, molar absorptivity of porphyrin in the coating is $165000 \mathrm{~cm}^{-1} \mathrm{M}^{-1}$ and density $1.58 \mathrm{~g} \mathrm{~cm}^{-3}$ (correlation coefficient of the linear fit in Fig. 12

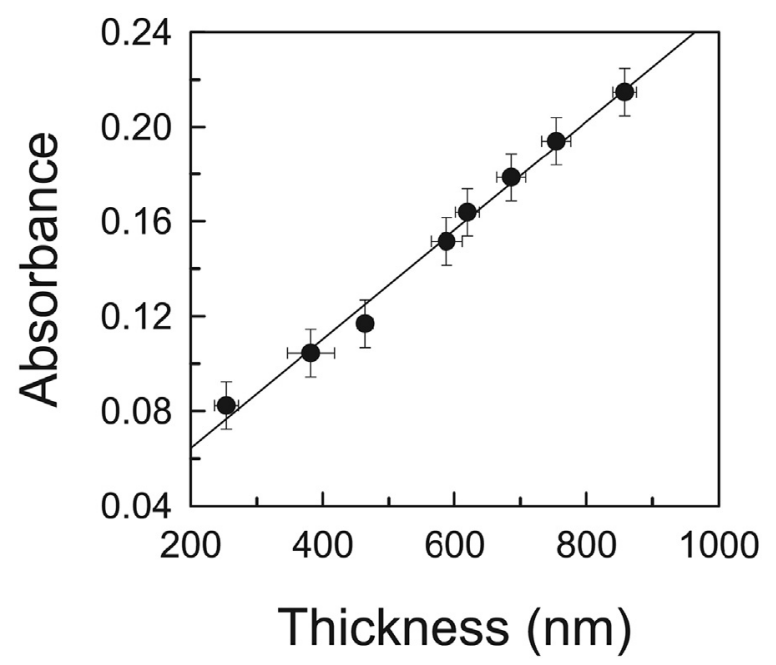

Fig. 12. Variation of the Soret absorption band at $433 \mathrm{~nm}$ with the coatings thickness. 
is 9.9915). Consequently, this estimated value of the molar absorptivity of the porphyrin in the coating is lower than in the methanol solution.

\subsubsection{Luminescence-thickness behavior}

Similarly to the case of optical absorption, luminescence of doped coatings increases with their thickness. However, the excitation increases throughout the whole measured wavelength range, whereas the absorption only increases near the Soret band maximum. To study the variation of excitation and emission spectra with the coatings thickness, the coatings were dipped into a $\mathrm{pH} 7$ buffered solution for 5 min.

The excitation spectra of 8 coatings with different thickness at $\lambda_{\mathrm{em}}=655 \mathrm{~nm}$ were recorded. The excitation maximum appears at $437 \mathrm{~nm}$, very near the excitation maximum of coatings reported above. For wavelengths below than $400 \mathrm{~nm}$ and above $460 \mathrm{~nm}$, the relation of order of the excitation maxima is maintained. This result indicates that the coatings excitation depends on the amount of molecules able to interact with the light beam, and that the thickness does not affect the mechanism. Obviously for a constant dopant concentration, the higher the thickness, the higher the excitation intensity. In Fig. 13 the variation of the excitation intensity at $437 \mathrm{~nm}$ is plotted against the coatings thickness. A good linear fit in this figure (correlation coefficient 0.9812) indicates that the coatings luminescence is a bulk phenomenon rather than a surface one.

If the luminescence were mainly generated on the surface, the contribution of the bulk molecules would be lower than those of the molecules near the surface, and then the variation with thickness would not vary linearly.

The emission spectra of doped coatings with different thickness (ranging from 254 to $858 \mathrm{~nm}$ ) show an intense band around $650 \mathrm{~nm}\left(\lambda_{\text {exc }}=437 \mathrm{~nm}\right)$. Once again, the higher the coating thickness, the higher the emission intensity, irrespective of the wavelength. The shape and wavelength of the emission maxima are equal to those of the emission spectra recorded with different $\mathrm{pH}$. The variation of the intensity of the emission maxima shows the same behavior against the coatings thickness as in Fig. 13 for the excitation intensity at $437 \mathrm{~nm}$.

\section{Discussion}

The interpretation of the porphyrin optical behavior, once encapsulated into a solid sol-gel thin coating, needs the

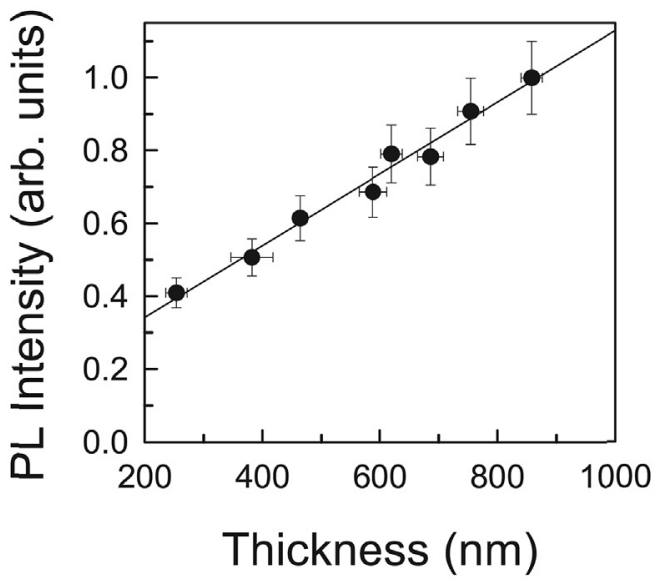

Fig. 13. Variation of the excitation intensity at $437 \mathrm{~nm}$ as a function of the doped coatings thickness. understanding of its behavior in solution. The same could be said on the encapsulated porphyrin behavior against the $\mathrm{pH}$ of the medium. In order to obtain well resolved spectra, the highest porphyrin concentration in methanol solution was investigated $\left(5.0 \times 10^{-5} \mathrm{M}\right)$, and the concentration range $10^{-6}-10^{-4} \mathrm{M}$ has been found for the Lambert-Beer law fulfilling.

Absorption spectra of the porphyrin in methanol solution are dominated by an intense Soret band and four $\mathrm{Q}$ bands. The Soret band shows a very high molar absorptivity $\left(\varepsilon>200000 \mathrm{~cm}^{-1} \mathrm{M}^{-1}\right)$ that reveals a transition probability near to one. Electronic transitions of $\mathrm{Q}$ bands are forbidden transitions with moderate molar absorptivity $\left(\varepsilon \sim 18000 \mathrm{~cm}^{-1} \mathrm{M}^{-1}\right)$. Their relative intensity in methanol solution is IV $>$ III $>$ II $>$ I, which corresponds to the etio type instead of filo type as predicted by the theory. However, that order is the same as in other porphyrins with similar structure, and both wavelengths and intensities are consistent with those found in the literature [28].

Luminescent excitation in methanol solution is similar but not equal to the absorption spectra. Main differences concern relative intensities: Soret band respect to $\mathrm{Q}$ bands decrease in the excitation spectra. An estimation of the quantum efficiency indicates that it is lower than $1 / 2$, which is consistent with the values found in the literature for other similar porphyrins [34,35] and metalloporphyrins [36]. The emission spectra show an intense band near $650 \mathrm{~nm}$ and a less intense one at about $710 \mathrm{~nm}$. Both maxima position and the band shape are similar to other found in the literature [28]. The quantum efficiency of the porphyrin in methanol solution is considerable, but it depends on the solution nature and its $\mathrm{pH}$.

Optical absorption of porphyrin in solutions with different $\mathrm{pH}$, changes both in wavelength and molar absorptivity. Such changes enable the study of the $\mathrm{pH}$ ranges in which the polyprotic transformations of the porphyrin take place. Even though the Soret band is the most affected by the $\mathrm{pH}$, the joint study with the $\mathrm{Q}$ bands behavior allows to know the protonation states of the porphyrin $[27,30]$. Some equilibrium constants have been estimated from the optical absorption spectra, being the error \pm 0.4 for $\mathrm{pK}_{1}, \mathrm{pK}_{2}$ and $\mathrm{pK}_{3}$, and \pm 1 for $\mathrm{pK}_{4}$. The error sources are connected with the limited intermediate $\mathrm{pH}$ values tested, the ionic strength of solutions, the error of the absorption measurements, and the weakness of some changes. The estimated values of $\mathrm{pK}_{1}$ and $\mathrm{pK}_{2}$ (0.8 and 2.0, respectively) are very similar to the literature values $[25,37,38]$. Concerning $\mathrm{pK}_{3}$ and $\mathrm{pK}_{4}$, no other values, apart from those estimated here, were found in the literature. However, the pK values of similar metalloporphyrins in aqueous solution (39) are very close to those we found here.

The slight variation of the Soret band and the $\mathrm{Q}$ bands in the $\mathrm{pH}$ range 7-11 could be compared with the behavior of other metalloprphyrins in the $\mathrm{pH}$ range $8-10$ not attributed to a polyprotic transformation (39), but to a kind of aggregate formation or dimmerization.

The comparison of wavelength and intensity of the absorption bands of the porphyrin in methanol solution and in the doped coatings once dipped into aqueous buffered solutions is possible, since the presence of water does not affect significantly these features [28]. Thus, such comparison indicates that the molecular configuration of the porphyrin in methanol solution is mainly monoanionic, even though the methanol has a slight acid character, but not enough to protonate the free base form of the porphyrin. Actually, the free base form results more acid than the methanol one. The predominance of the monoanionic form in methanol solution can be attributed to the higher electrostatic stability of this configuration.

The behavior of the porphyrin excitation spectra in solutions of different $\mathrm{pH}$ is similar to that observed in the corresponding 
absorption spectra. The differences detected in the excitation spectra involve wider Soret bands and higher relative intensity of Q bands. Moreover, the analysis of excitation spectra also allows determining the $\mathrm{pK}$ values in solution. The maximum peak of the excitation Soret band behaves against the $\mathrm{pH}$ in a different way than the absorption one, and its maximum intensity is observed for the $\mathrm{pH}$ range $3-5$, i.e., when the porphyrin molecule takes the monocationic form. However, the corresponding wavelength evolution against $\mathrm{pH}$ is the same as observed for the Soret absorption band. The emission spectra of the porphyrin $\left(\lambda_{\text {exc }}=420 \mathrm{~nm}\right)$ for different $\mathrm{pH}$ show a main band at $655 \mathrm{~nm}$ and a secondary one at wavelength higher than $700 \mathrm{~nm}$. The maximum intensity of emission takes place for $\mathrm{pH}=3$, i.e., when the porphyrin molecule is in monocationic form, and changes in the $\mathrm{pH}$ ranges of $0-3$ and 10-13.4. Such changes could be associated with the porphyrin polyprotic forms.

Two experiments were carried out to analyze the porphyrin behavior against the $\mathrm{pH}$, once encapsulated in the thin coatings. On the one hand, the doped coating was successively dipped in buffered solutions with increasing $\mathrm{pH}$ and decreasing $\mathrm{pH}$ : the results indicate that doped coatings behave in a different way than the porphyrin in methanol solution, i.e. the number of transformations and the $\mathrm{pH}$ at which they occur is different; the encapsulated porphyrin submit reversible transformations with the $\mathrm{pH}$ changes, but some hysteresis takes place. On the other hand, the doped coatings were alternatively dipped into two extreme $\mathrm{pH}$ buffered solutions: little sensitivity against $\mathrm{pH}$ changes was detected, since the Soret band maximum is practically constant and the free base form of the porphyrin molecule predominates. Nevertheless, as the doped coating is submitted to an increased $\mathrm{pH}$, some molecules in the free base form are reversibly transformed into the monoanionic form (the absorption increases and the wavelength decreases).

According to the results obtained, the sol-gel matrix induce small shift in the Soret band and slightly higher in the $Q$ bands. Although in the literature such shift is usually attributed to interaction with the silanol groups $(\equiv \mathrm{Si}-\mathrm{OH})$ of the coatings silica matrix (40), the present interpretation correlates the maxima wavelengths with the polyprotic forms, since the absorption bands features (maximum wavelength and evolution against $\mathrm{pH}$ ) are very similar to the porphyrin behavior in methanol solution.

Reversibility tests of the doped coatings absorption in two extreme $\mathrm{pH}$ pointed out that the coating sensitivity increases with the number of alternative dipping into acid and basic buffered solutions. The reversibility of the doped coating could be considered good, but the measured reproducibility is not. Moreover, after all the dipping cycles, no leaching or washing of the porphyrin molecules was detected.

Basically, the excitation spectra of doped coatings are similar to the corresponding absorption spectra and clearly show the Q IV and II bands. As regards the Soret band, its intensity increases with $\mathrm{pH}$ but not monotonically. The emission spectra of the doped coating against $\mathrm{pH}$ showed very slight intensity changes, even though the intensity increases with $\mathrm{pH}$, particularly in the 6-8 range.

The profile of the absorption spectra of doped coatings with different thickness is the same as the spectra recorded at $\mathrm{pH}=7$. The evolution of the absorption intensity with thickness follows a linear relation. The corresponding least squares fitting is adequate to describe the doped coatings behavior and the Lambert-Beer law is fulfilled. From the best fitting of the Soret band features against thickness, the data of the coatings density and the porphyrin concentration in the solid thin coating, the molar absorptivity of the porphyrin in the coating has been estimated. The found values show that the molar absorptivity decreases respect to the value in solution. Therefore, the assumption that the molar absorptivity of each porphyrin molecule in the coating is the same as in solution is discarded, because the corresponding density values obtained are too low respect to those expected.

Finally, the luminescence of doped coatings for different thickness showed that both excitation and emission behave linearly against the thickness. The linear dependence of luminescence with the thickness is an experimental confirmation that this phenomenon takes place in the whole coating bulk rather than on its surface.

\section{Conclusions}

The analysis of the optical behavior of the porphyrin studied in methanol solution demonstrates that both absorption and luminescence vary with the $\mathrm{pH}$ of the solution. Such variations are due to the porphyrin molecule that shows four polyprotic transformations: $\mathrm{pK}_{1}=0.8, \mathrm{pK}_{2}=2.0, \mathrm{pK}_{3}=5.5$ and $\mathrm{pK}_{4} \sim 13$.

Soret absorption band of the porphyrin in methanol solution takes different position depending on the polyprotic state of the molecule (maxima at: $446 \mathrm{~nm}$ dicationic form, $423 \mathrm{~nm}$ monocationic form, $435 \mathrm{~nm}$ neutral form, $423 \mathrm{~nm}$ monoanionic form, and $425 \mathrm{~nm}$ dianionic form). The relative intensity of the four $\mathrm{Q}$ bands in solution is very sensitive against the polyprotic state of the porphyrin ring.

The luminescence of the porphyrin in solution indicates that the emission maximum of the cationic forms occurs near $660-655 \mathrm{~nm}$, while for neutral and anionic forms, it takes place at about $645-650 \mathrm{~nm}$. The main excitation maximum in solutions corresponds to the position of the Soret absorption maximum for the $\mathrm{pH}$ range checked (0-13.4).

In the porphyrin doped coating, the main absorption band is the Soret one, whose maximum occurs at $433 \mathrm{~nm}$ throughout the $\mathrm{pH}$ range studied. In the doped coating the free base form predominates for all the $\mathrm{pH}$ values.

Luminescent emission of doped coating shows its maximum at about $653 \mathrm{~nm}$. The excitation wavelength used was $436 \mathrm{~nm}$ and no tendency was observed for different $\mathrm{pH}$.

The Soret absorption band of coatings doped with 1 wt \% porphyrin with different thickness obey the Lambert-Beer law. The molar absorptivity of the porphyrin once encapsulated into the thin sol-gel coating is much lower than in solution.

\section{Acknowledgements}

This work has been supported by the Ministerio Español de Economia y Competitividad (MINECO) projects ref. MAT201238045-C04-03, MAT2013-48009-C4-1, MAT2015-65445-C2-1-R and MAT2015-65445-C2-2-R.

\section{References}

[1] D. Avnir, S. Braun, M. Ottolenghi, Encapsulation of organic molecules and enzymes in Sol-Gel glasses. A review of novel photoactive, optical, sensing, and bioactive materials, in: Supramolecular Architecture, Chapter 27 384-404, ACS Symposium Series, Vol. 499, American Chemical Society, 1992.

[2] K. Matsui, Entrapment of organic molecules (Chapter 20), in: Sumio Sakka, Hiromitsu Kozuka (Eds.), Handbook of Sol-gel Science and Technology. Processing, Characterization and Applications, Sol-gel Processing, Vol. 1, Kluwer Academic Publishers, 2005.

[3] N. Carmona, E. Herrero, J. Llopis, Villegas. M.A. Chemical sol-gel based sensors for evaluation of environmental humidity, Sens. Actuat B-Chem 126 (2) (2007) $455-460$.

[4] J. Dargiewicz-Nowicka, M. Makarska, M.A. Villegas, J. Legendziewicz, St Radzki, Photophysics of the porphyrins; unusual luminescence of europium porphyrin complex entrapped in sol-gel silica matrix, J. Alloy Compd. 380 (1-2) (2004) 380-388.

[5] Z. Dudas, C. Enache, G. Fagadar-Cosma, I. Armeanu, E. Fagadar-Cosma, Hybrid silica-porphyrin materials with tailored pore sizes, Mater Res. Bull. 45 (9) (2010) 1150-1156.

[6] C.-S. Chu, C.-Y. Chuang, Optical fiber sensor for dual sensing of dissolved oxygen and $\mathrm{Cu}^{2+}$ ions based on PdTFPP/CdSe embedded in sol-gel matrix, Sens. Actuat B-Chem 209 (2015) 94-99. 
[7] C.-S. Chu, Y.-L. Lo, T.-W. Sung, Enhanced oxygen sensing properties of Pt(II) complex and dye entrapped core-shell silica nanoparticles embedded in solgel matrix, Talanta 82 (3) (2010) 1044-1051.

[8] V.S. Tripathi, G. Lakshminarayana, M. Nogami, Optical oxygen sensors based on platinum porphyrin dyes encapsulated in ORMOSILS, Sensors Actuators, B Chem. 147 (2) (2010) 741-747.

[9] S.-K. Lee, I. Okura, Optical sensor for oxygen using a porphyrin-doped sol-ge glass, Analyst 122 (1997) 81-84.

[10] V.S. Tripathi, G. Lakshminarayana, M. Nogami, Optical oxygen sensors based on platinum porphyrin dyes encapsulated in ORMOSILS, Sens. Actuat B-Chem 147 (2) (2010) 741-747.

[11] E. Fagadar-Cosma, Z. Dudás, M. Birdeanu, L. Almásy, Hybrid organic - silica nanomaterials based on novel A3B mixed substituted porphyrins, Mater Chem. Phys. $148(1-2)(2014)$ 143-152.

[12] I. Hajime, S. Katsuhiko, S. Yasuhiro, K. Hidemasa, Spectrophotometric and analogue derivative spectrophotometric determination of ultramicro amounts of cadmium with cationic porphyrins, Talanta 29 (1982) 545-550.

[13] T. Masaaki, M. Hirofumi, Spectrophotometric determination of a nanomolar amount of ascorbic acid using its catalytic effect on copper (II) porphyrin formation, Talanta 44 (1997) 151-157.

[14] J. Manriquez, J.L. Bravo, S. Gutierrez-Granados, S. Sucar, C. Bied-Charreton, A. Alatorre Ordaz, F. Bedioui, Electrocatalysis of the oxidation of alcohol and phenol derivative pollutants at vitreous carbon electrode coated by nicke macrocyclic complex-based films, Anal. Chim. Acta 378 (1999) 159-168.

[15] M.F. Nepomuceno, M. Tabak, A.E. Vercesi, Opposite effects of $\mathrm{Mn}(\mathrm{III})$ and Fe (III) forms of meso-tetrakis (4-N-methyl pyridiniumyl) porphyrins on isolated rat liver mitochondria, J. Bioenerg. Biomembr. 34 (1) (2002) 41-47.

[16] S.C.M. Gandini, I.E. Borissevitch, J.R. Perussi, H. Imasato, M. Tabak, Aggregation of meso-tetrakis (4-N-methyl-pyridiniumyl) porphyrin in its free base, Fe (III) and $\mathrm{Mn}$ (III) forms due to the interaction with DNA in aqueous solutions: optical absorption, fluorescence and light scattering studies, J. Lumin 78 (1998) 53-61.

[17] J. Lee Kang, K. Lee, V. Castranova, Nitric oxide up-regulates DNA-binding activity of nuclear factor-kB in macrophages stimulated with silica and inflammatory stimulants, Mol. Cell Biochem. 215 (1-2) (2000) 1-9.

[18] P.M. Dias, D.L.A. De Faria, V.R.L. Constantino, Spectroscopic studies on the interaction of tetramethylpyridylporphyrins and cationic clays, J. Incl Phenom. 38 (1-4) (2000) 251-266.

[19] J. Dargiewicz, M.A. Villegas, S. Radzki, Optical spectroscopy of porphyrins and their metal complexes in sol-gel monoliths and thin film coatings, in: Third Int. Conf. On Progress in Inorg. and Organometallic Chem. Polanica Zdrój, Poland, Sep. 17-22, 2000, p. 50.

[20] D. Delmarre, C. Bied-Charreton, Grafting of cobalt porphyrins in sol-ge matrices: application to the detection of amines, Sens. Actuat B-Chem 62 (2) (2000) 136-142.

[21] E. Montero, M.A. García, M.A. Villegas, J. Llopis, Spectral pH dependence of erythrosin B in sol-gel silica coatings and buffered solutions, Bol. Soc. Esp.
Ceram. V. 47 (1) (2008) 1-6.

[22] M.A. Villegas, L. Pascual, Sol-gel silica coatings doped with a $\mathrm{pH}$ sensitive chromophore, Thin Solid Films 351 (1-2) (1999) 103-108.

[23] E.F. Montero, M.A. García, M.A. Villegas, J. Llopis, Study of optical properties of fluorescein-doped sol-gel coatings as a function of concentration and $\mathrm{pH}, \mathrm{Bol}$. Soc. Esp. Ceram. V. 43 (1) (2004) 8-11.

[24] K. Kano, H. Minamizono, T. Kitae, S. Negi, Self-aggregation of cationic porphyrins in water. Can $\pi-\tau$ staking interaction overcome electrostatic repulsive force, J. Phys. Chem. A 101 (34) (1997) 6118-6124.

[25] R.F. Pasternak, N. Sutin, D.H. Turner, Some very rapid reactions of porphyrins in aqueous solution, J. Am. Chem. Soc. 98 (7) (1976) 1908-1913.

[26] D. Dolphin, The Porphyrins, vol. 3, Academic Press, New York, USA, 1978.

[27] J.E. Falk, Porphyrins and Metalloporphyrins, in: B.B.A. Library, vol. 2, Elsevier, Amsterdam, 1964.

[28] M. Makarska, S. Radzki, J. Legendziewicz, Spectroscopic characterization of the water-soluble cationic porphyrins and their complexes with $\mathrm{Cu}(\mathrm{II})$ in various solvents, J. Alloy Compd. 341 (2002) 233-238.

[29] R.F. Pasternak, P.R. Huber, P. Boyd, G. Engasser, L. Francesconi, E. Gibbs, P. Fasella, G. Cerio Venturo, L. de C. Hinds,. On the aggregation of mesosubstituted water-soluble porphyrins, J. Am. Chem. Soc. 94 (13) (1972) 4511-4517.

[30] L.R. Milgrom, The Colours of Life: an Introduction to the Chemistry of Porphyrins and Related Compounds, first ed., Oxford Univ. Press, England, 1997 (chapter 3).

[31] R.L. Brookfield, H. Ellul, A. Harriman, Luminescence of porphyrins and metalloporphyrins IX: dimmerization of meso-tetrakis (N-methyl-4-pyridyl)porphine, J. Photochem 31 (1985) 97-103.

[32] E.F. Montero Zeledón, Espectroscopía óptica de recubrimientos sol-gel de sílice sensibilizados con moléculas orgánicas, PhD dissertation, Universidad Complutense, Madrid, 2014.

[33] D. Delmarre, R. Méallet-Renault, C. Bied-Charreton, R.F. Pasternak, Incorporation of water-soluble porphyrins in sol-gel matrices and application to $\mathrm{pH}$ sensing, Anal. Chim. Acta 401 (1999) 125-128.

[34] P.G. Seybold, M. Gouterman, Porphyrins XIII: fluorescence spectra and quantum yields, J. Mol. Spectrosc. 31 (1969) 1-13.

[35] O. Ohno, Y. Kaizu, H. Kobayashi, Luminescence of some metalloporphyrins including the complexes of the IIIb metal group, J. Chem. Phys. 82 (1985) 1779-1787.

[36] Z.M. Abou-Gamra, N.M. Guindy, Photochemistry of metalloporphyrins in aqueous solutions, Spectrochim. Acta A 45 (12) (1989) 1207-1210.

[37] H. Baker, P. Hambright, L. Wagner, Metal ion porphyrin interactions. II. Evidence for the nonexistence of sitting atop complexes in aqueous solution, J. Am. Chem. Soc. 95 (18) (1973) 5942-5946.

[38] H. Inoue, T. Iwamoto, A. Makishima, M. Ikemoto, K. Horie, Preparation and properties of sol-gel thin films with porphyrins, J. Opt. Soc. Am. B 9 (5) (1992) 816-818. 